Revista Educação e Políticas em Debate - v. 7, n. 1, p. 77-94-jan./abr. 2018 - ISSN 2238-8346

\title{
Políticas públicas para a educação do campo e formação de professores no Brasil
}

\author{
Public policies for rural education and teacher training in Brazil \\ Politiques publiques pour l'éducation rurale et la formation des enseignants au Bresil
}

\author{
Suze da Silva Sales ${ }^{1}$ \\ Universidade Federal do Tocantins \\ Alessandro Rodrigues Pimenta ${ }^{2}$ \\ Universidade Federal do Tocantins
}

Resumo: O artigo tem por objetivo analisar fatores e sujeitos determinantes no percurso de implantação da política pública de criação de cursos de formação de professores para atuarem em escolas do/no campo. Tais políticas ganharam força a partir da primeira década dos anos 2000, quando movimentos sociais ligados à terra, apoiados e financiados direta/indiretamente por organismos nacionais e internacionais, encontraram momentos profícuos à conquista e à institucionalização de Licenciaturas em Educação do Campo, planejadas e financiadas pelo Estado brasileiro, via Ministério da Educação e propostas por Instituições Federais de Ensino Superior. Almeja-se que tais análises possam oferecer subsídios para a ampliação das discussões sobre as políticas destinadas às populações campesinas no Brasil.

Palavras-chave: Formação de professores. Políticas públicas para Educação. Educação do Campo.

\begin{abstract}
The objective of this article is to analyze factors and subjects in the implementation of the public policy of creating teacher training courses to work in schools in the countryside. These policies gained momentum starting in the first decade of the 2000s, when social movements linked to the land, supported and financed directly or indirectly by national and international organizations, found fruitful moments for the conquest and institutionalization of Field Education Licenses, planned and financed by the Brazilian State, through the Ministry of Education and proposals by Federal Institutions of Higher Education. It is hoped that such analyzes may provide subsidies for the expansion of the discussion on policies aimed at peasant populations in Brazil.
\end{abstract}

Key words: Teacher training. Public policies of Education. Rural Education.

Résumé: L'objectif de cet article est d'analyser les facteurs et les sujets déterminants dans la mise en œuvre de la politique publique de création de cours de formation des enseignants pour travailler dans les écoles à la campagne. Ces politiques ont pris de l'ampleur à partir de la première décennie des années 2000, lorsque des mouvements sociaux liés à la terre, soutenus et financés directement ou indirectement par des organisations nationales et internationales, ont trouvé des moments fructueux pour la conquête et l'institutionnalisation

\footnotetext{
${ }^{1}$ Doutora em Educação. Professora Assistente na Universidade Federal do Tocantins. suze@uft.edu.br

${ }^{2}$ Doutor em Filosofia. Professor Adjunto da Universidade Federal do Tocantins. Coordenador Institucional da Escola da Terra na UFT. E-mail.pimenta@uft.edu.br
} 
des permis d'éducation. par l'État brésilien, par l'intermédiaire du ministère de l'Éducation et des propositions des institutions fédérales d'enseignement supérieur. Il est à espérer que de telles analyses pourraient fournir des subventions pour l'expansion de la discussion sur les politiques visant les populations paysannes au Brésil.

Mots-clés: Formation des enseignants. Politiques publiques pour l'éducation. Education rurale.

\section{Introdução}

A política pública para formação de professores no Brasil se constitui em objeto de estudo que vem sendo pesquisado e discutido no meio acadêmico, cuja produção de conhecimentos aumentou substancialmente nas últimas décadas do século XX, a partir dos anos de 1980 e nas décadas iniciais do século XXI. As campanhas para democratização do acesso e permanência nas escolas, com slogans do tipo "Toda criança na escola", o advento de marcos legais, como a promulgação da Lei de Diretrizes e Bases da Educação Nacional LDB de n. 9.394, em 1996, que postulou a necessidade de formação em nível superior como requisito para docência -, podem ser lembrados como alguns dos fatores que contribuíram para a ampliação dos debates em relação à formação de professores no país.

Seguindo essa tendência de estudos sobre a formação de professores, o presente artigo se soma a essa produção, estando relacionado à política de formação para docência nas escolas do/no campo, ou seja, às Licenciaturas em Educação do Campo - LEdoC, planejadas e financiadas pelo Estado brasileiro, via Ministério da Educação - MEC e que visam formar, principalmente, mas não exclusivamente, professores para atuarem em escolas no campo, que são as instituições formais de ensino situadas no meio rural ou escolas do campo, alocadas em áreas rural ou urbana, desde que recebam a maior parte de seus alunos oriundos do meio rural.

Se o estudo envolvendo a temática de formação de professores em nível superior é algo importante e novo no país, os estudos que enfocam as licenciaturas com especificidade para docência em escolas no campo são ainda mais recentes. É importante lembrar que a preocupação em formar docentes para áreas rurais já estava posta no ideário pedagógico nacional nas primeiras décadas do século XX. Entretanto, àquela época, essa formação se 
dava em nível médio, em cursos normais. Diferente desta, a formação da qual tratará este artigo é a ofertada sob responsabilidade do MEC e das Instituições Federais de Ensino Superior - IFES. Formação pleiteada por um conjunto de instituições e movimentos sociais organizados no que ficou conhecido como "Movimento Nacional por uma Educação do Campo", cujas ações perpassaram os anos finais de 1990, chegando até aos dias atuais, ano de 2018.

Anseia-se que tais análises, baseadas em autores que tratam da temática em questão, nos marcos normativos da Educação do Campo e nos editais para implantação/institucionalização de LEdoCs, possam oferecer subsídios para a ampliação das discussões sobre as políticas destinadas às populações campesinas no Brasil e que se autojustificam pelo atendimento às exigências e expectativas dos movimentos sociais organizados ligados à terra. Exigências que deram origem a um cabedal de dispositivos, os quais tornam possível aventar a possibilidade da existência de uma política pública estatal ${ }^{3}$ para a educação dos povos do campo no Brasil.

\section{Educação Rural e Educação do Campo: duas vertentes presentes na educação das populações rurais}

Historicamente, o termo "Educação Rural" foi associado à precariedade, à falta de conhecimento da cultura e das coisas do campo, à ausência de prédios, materiais didáticos, transporte. Eram (e ainda o são, haja vista o número significativo dessas escolas, principalmente nas regiões Norte e Nordeste) escolas caracterizadas pela prevalência das classes multisseriadas, que reúnem, num mesmo espaço, dois, três, quatro ou mais anos de escolaridade, ficando estas sob a responsabilidade de um único professor. Destacam-se, também, a ausência de formação adequada para docência no campo e a total desvinculação aos anseios dos sujeitos e povos do campo. O termo "Educação Rural” passou a corresponder, assim, a este quadro tenebroso de ausência de políticas públicas e participação efetiva dos sujeitos do campo, estando atrelado ao clássico modelo do grande latifúndio e às aspirações do capital rural. "O sentido da educação rural aparece quando há referência à política educacional do início e decorrer do século XX, cuja preocupação era com ações que pudessem

\footnotetext{
${ }^{3}$ Quando nos referimos a políticas públicas estatais, fazemos menção às ações que compõem a esfera do Estado, sendo planejadas e colocadas em prática pelo mesmo. Sobre esta discussão, Cf.: COSTA, Sidiney Alves; BEZERRA NETO, Luiz. Políticas públicas/estatais: contribuição para o estudo da relação estadosociedade. Acta Scientiarum Education. Maringá, v. 38, n. 2, p. 165-172, Abr.-Jun., 2016.
} 
superar o 'atraso' presente entre os trabalhadores e moradores do espaço rural” (SOUZA, 2006, p. 51).

Em contrapartida ao termo "Educação Rural”, passou-se a utilizar o termo "Educação do Campo". Este termo não se configura como uma simples troca de palavras, mas uma tentativa de firmar uma diferenciação clara das escolas existentes, em boa medida, capengas e precárias, que povoavam (e ainda povoam) o campo brasileiro. O termo "do Campo" vem para rechaçar a visão dessa escola. Dessa forma,

[...] o sentido de Educação do Campo aparecerá quando estiver em destaque a ação dos movimentos sociais e as parcerias em desenvolvimento nesse início de século, oriundas da dinâmica social do campo no final do século $\mathrm{XX}$. É um conceito configurado a partir da ação dos movimentos sociais do campo destacando os aspectos da identidade e da cultura. Na atualidade, o campo aparece nas propostas educacionais dos movimentos sociais com a ideia de valorização do trabalhador que atua no campo, que possui laços culturais e valores relacionados à vida na terra (SOUZA, 2006, p. 51).

Posterior aos anos de 1980, várias ações foram empreitadas por sujeitos coletivos, sendo o Movimento dos Trabalhadores Sem Terra - MST, um dos protagonistas ${ }^{4}$ da Conferência Nacional por uma Educação Básica do Campo, que ocorreu em Luziânia, estado de Goiás, em julho de 1998, que vem sendo reconhecida como marco das discussões sobre Educação do Campo, sendo, de acordo com Munarim, (2008, p. 7), “[...] a primeira Conferência Nacional da área”. Nesta Conferência, ao MST, se somaram: a Universidade de Brasília - UNB, a United Nations Children's Fund - Unicef, em português: Fundação das Nações Unidas para a Infância; a United Nations Educational, Scientific and Cultural Organization - Unesco, em português: Organização das Nações Unidas para a Educação, a Ciência e a Cultura e a Conferência Nacional dos Bispos do Brasil - CNBB.

O termo "Educação do Campo" passou, assim, a ser utilizado amplamente para escolas que estejam no campo ou que, mesmo estando na cidade recebem grande parte de seus alunos advindos do campo. Entretanto, se a Educação do Campo pleiteada pelos movimentos sociais ligados a terra tem como condição sine qua non a " $[\ldots]$ a ação dos movimentos sociais e as parcerias em desenvolvimento nesse início de século, oriundas da dinâmica social do campo

\footnotetext{
${ }^{4}$ Nas discussões sobre políticas públicas, ao final dos anos de 1990 e anos 2000, aparece com destaque a categoria que Gohn (2005, p. 9) denomina como "protagonismo da sociedade civil”. Para esta autora, "a palavra protagonismo vem do grego e o termo designava o lutador principal de um torneio. Depois a palavra passou a ser usada para designar os atores principais de um enredo teatral ou os personagens principais de uma trama literária. Recentemente, as ciências humanas não só se apoderaram do termo ator como passaram a utilizar o próprio termo protagonismo para os atores que configuram as ações de um movimento social” (grifos da autora).
} 
no final do século XX (SOUZA, 2006, p. 51)”, é possível pressupor que nem todas as escolas que estão nessa situação, alocadas no meio rural ou na cidade, com predominância de alunos campesinos, possam desenvolver, de fato, uma "Educação do Campo".

Um ponto marcante na diferenciação desses dois termos se deu em 2002, como consequência das ações dos movimentos sociais populares organizados, conforme afirmado anteriormente, quando o Conselho Nacional de Educação-CNE aprovou as "Diretrizes Operacionais para a Educação Básica nas Escolas do Campo” e ratificou no texto do Parecer $n^{\circ} 36$ de 2001, o conceito de Educação do Campo, tal como formulado na I Conferência:

a educação do campo, tratada como educação rural na legislação brasileira, tem um significado que incorpora os espaços da floresta, da pecuária, das minas e da agricultura, mas os ultrapassa ao acolher em si os espaços pesqueiros, caiçaras, ribeirinhos e extrativistas. O campo, nesse sentido, mais do que um perímetro não-urbano, é um campo de possibilidades que dinamizam a ligação dos seres humanos com a própria produção das condições da existência social e com as realizações da sociedade humana (BRASIL, 2001, p. 1).

Para se chegar aos anos iniciais do século XXI com esta visão de "Educação do Campo", é preciso compreender que o país se caracterizou como agrário-exportador de commodities, ou seja, de produtos in natura ou pouco industrializados. A produção do campo, o êxodo rural que superpovoou grandes centros urbanos, a oferta e procura de mão-de-obra, a luta pela terra, dentre outros aspectos, sempre foram fatos marcantes em nossa sociedade. Nessa relação, criou-se uma visão de contradição entre "urbano versus rural”, como se essas realidades não fizessem parte de uma totalidade. Este é um erro recorrente, sobretudo, em pesquisas na área em questão neste estudo, a saber, a Educação ${ }^{5}$.

\section{Educação do Campo no Brasil: cenários interno e externo favoráveis ao aparecimento de políticas públicas}

\footnotetext{
${ }^{5}$ Em sua tese, Oliveira (2008), chama a atenção para o fato de que é comum encontrar em alguns autores que pesquisam a temática da Educação do Campo, uma visão fragmentária de urbano e rural. Visão que desconsidera que estas duas vertentes são parte constituinte de um todo, não cabendo a análise de qualquer das partes sem a devida consideração à outra. Elas são complementares e dependentes.
} 
A dependência de fomento estrangeiro para investimentos na área da economia fez com que o Brasil se adequasse aos postulados e diretrizes de organismos internacionais, como o Banco Mundial - BM em áreas entendidas como estratégicas, como a educação.

Partindo das necessidades econômicas, geradas no setor produtivo e nas formas como ele se estrutura e se organiza, o BM destaca o papel da educação para o desenvolvimento das sociedades contemporâneas. Depois de mostrar as altas taxas de retorno trazidas por investimentos no campo educacional, o BM define políticas, nesse campo, para países do terceiro mundo com objetivo de melhorar a sua competitividade no mercado internacional, identificando a distribuição desigual e a baixa qualidade da educação oferecida à maioria da população dos países em desenvolvimento, o BM (...) defende a ideia da equidade em educação, como condição para eficiência econômica global (SANTOS, 2000, p. 173).

Essa determinação por instrução vai traçar e delinear os pressupostos educacionais defendidos pelo BM. Tendo em vista que não há como conduzir a instrução formal presencial (escolas e universidades) sem professores e que as estatísticas educacionais apontavam e apontam para um déficit quanto à oferta de mão-de-obra docente devidamente capacitada, não há de se estranhar que a formação de professores foi uma das frentes apoiada e promovida. Sobre este assunto, há autores que se debruçaram em compreender como a formação de professores, nesse caso no Brasil, vai se adequar à lógica do capital 7 .

De modo concomitante ao cenário econômico traçado, seguiu-se um período de redemocratização, de retomada de movimentos organizados e representativos de parcelas até então silenciadas pelo período da ditadura civil militar (1964-1985). As relações sociais, nesse contexto, sofreram transformações e surgiram novos sujeitos coletivos ${ }^{8}$, os movimentos sociais. Por “movimentos sociais" entende-se:

\footnotetext{
${ }^{6}$ De acordo com Lima (2004, p. 4), “o Banco Mundial é um organismo financeiro internacional de cooperação multilateral, criado em 1944 através da Conferência de Bretton Woods e a partir de uma iniciativa norteamericana. Tem em seu quadro cinco agências especializadas e dentre seus órgãos os mais importantes são: Junta de Governadores, Diretoria Executiva e Presidência. Criado para promover a reestruturação das economias devastadas pela $2^{\text {a }}$ Guerra, mudou seu marco de atuação, adotando o desenvolvimento e a redução da pobreza como áreas de ação. Para isso foca seus projetos em setores como a educação, atrelando-a ao crescimento econômico dos países membros".

${ }^{7}$ Cf. Santos (2000); Martins (2001); Martins e Duarte (2010).

${ }^{8} \mathrm{O}$ meio rural, historicamente, foi palco de lutas e movimentos de resistência como, das ligas camponesas e sindicatos rurais, que atuaram até o início da ditadura militar (1964). "A liga camponesa e o sindicato rural, [...], são contemporâneos. Surgem na mesma época, quando se dá o divórcio definitivo entre o lavrador e a propriedade dos meios de produção. São criados quando se rompe a base do 'universo comunitário' em que o fazendeiro, o capataz e o lavrador apareciam com membros de um mesmo nós coletivo. Isto é, a liga e o sindicato clarificam as fronteiras reais (econômicas, sociais, culturais, políticas, ideológicas) que dividem o fazendeiro e o trabalhador rural, quando o lavrador se transforma em proletariado" (IANNI, 1984, p.124). A atuação dos sindicatos e das ligas não se estendeu após o golpe de 1964, quando estas foram consideradas irregulares e aqueles sofreram a intervenção direta do governo ditatorial.
} 
[...] um conjunto mais abrangente de práticas sociopolítico-culturais que visam a realização de um projeto de mudança (social, sistêmica ou civilizatória), resultante de múltiplas realidades de relações sociais entre sujeitos e associações civis. É o entrelaçamento da utopia com o acontecimento, dos valores e representações simbólicas com o fazer político, ou com múltiplas práticas efetivas. [...]. Portanto, movimento social é a síntese de múltiplas práticas, produto das articulações de sujeitos e associações civis (SCHERER-WARREN, 1999, p. 16).

Desses movimentos sociais que emergem, destacou-se o MST, posteriormente denominado de Movimento dos Trabalhadores Rurais Sem Terra, organizado nacionalmente em 1984, num momento em que se aumentava a concentração de terras improdutivas e a expulsão dos pobres das áreas rurais, devido à modernização da agricultura e à crise do processo de colonização implementado pelo regime civil militar.

O projeto de sociedade do MST tinha como base os ideais das Ligas Camponesas do final dos anos de 1950 e início dos anos de 1960, a saber, desarticulado do Estado e autônomo quanto às ações, o que incluía a parte educacional. A equidade social, nesta visão, seria fruto de uma reforma agrária eficiente e de recursos que tornassem viável o trabalho rural dos expropriados da terra e, que a partir de então, seriam assentados da reforma agrária.

No contexto dessa luta, em 2002, o advento das Diretrizes Operacionais para a Educação Básica nas Escolas do Campo se tornou um importante marco regulatório na luta por uma educação para os campesinos. Posteriormente a este marco, seguem-se outras ações no âmbito estatal que, juntamente com a ação dos movimentos sociais, vão continuar fomentando o debate e dando visibilidade a esta modalidade de ensino.

Em 2004, o MEC cria a Secretaria de Educação Continuada, Alfabetização e Diversidade e Inclusão ${ }^{9}$. De acordo com o site oficial, o objetivo da SECADI é contribuir para a redução das desigualdades educacionais por meio da participação de todos os cidadãos em políticas públicas que assegurem a ampliação do acesso à educação. Dentre as ações da SECADI para atingir o objetivo explicitado acima, estão as relacionadas aos campesinos,

\footnotetext{
${ }^{9}$ Criada em 2004 como Secretaria de Educação Continuada, Alfabetização e Diversidade,-SECAD, em 2011 englobou as ações estatais para diversidade, sendo renomeada como Secretaria de Educação Continuada, Alfabetização, Diversidade e Inclusão (SECADI) que, de acordo com dados oficiais "em articulação com os sistemas de ensino implementa políticas educacionais nas áreas de alfabetização e educação de jovens e adultos, educação ambiental, educação em direitos humanos, educação especial, do campo, escolar indígena, quilombola e educação para as relações étnico-raciais. O objetivo da SECADI apresentado ao público é o de contribuir para o desenvolvimento inclusivo dos sistemas de ensino, voltado à valorização das diferenças e da diversidade, à promoção da educação inclusiva, dos direitos humanos e da sustentabilidade socioambiental, visando à efetivação de políticas públicas transversais e Inter setoriais” Disponível em: <http://portal.mec.gov.br/secretaria-de-educacao-continuada-alfabetizacao-diversidade-e-
} inclusao/apresentacao>. Acesso em 20/09/2016. 
como o "Escola Ativa" - já desativado e substituído pelo "Escola da Terra", o "Projovem Campo" e o "Procampo".

O programa "Escola Ativa" buscou capacitar recursos humanos e melhorar as condições materiais do trabalho pedagógico em escolas de classes multisseriadas (as que são caracterizadas por um único professor trabalhando com 2, 3 ou mais séries ao mesmo tempo). Já o "Escola da Terra", tem o objetivo de

\begin{abstract}
promover a melhoria das condições de acesso, permanência e aprendizagem dos estudantes do campo e quilombolas em suas comunidades, por meio do apoio à formação de professores que atuam nas turmas dos anos iniciais do ensino fundamental compostas por estudantes de variadas idades, e em escolas de comunidades quilombolas, fortalecendo a escola como espaço de vivência social e cultural (BRASIL, 2018) ${ }^{10}$.
\end{abstract}

É um programa que pressupõe a parceria entre os entes federados, Governo Federal, Estados e Municípios, cujas formações ficam a cargo de Universidades Federais, as quais têm autonomia para definir o projeto pedagógico desses cursos, conforme a região em que estão alocadas.

O Projovem do Campo - Saberes da Terra, segundo o site oficial, procura "oferecer qualificação profissional e escolarização aos jovens agricultores familiares de 18 a 29 anos que não concluíram o ensino fundamental”. Através de uma bolsa de estudos, o programa visa incentivar o retorno desses jovens à escola de qualidade, revertendo, assim, o quadro atual dessa “[...] parcela da população historicamente excluídas do processo educacional, respeitando as características, necessidades e pluralidade de gênero, étnico-racial, cultural, geracional, política, econômica, territorial e produtivas dos povos do campo" (BRASIL, 2018 $)^{11}$. O Procampo, Programa de Apoio à Formação Superior em Licenciatura em Educação do Campo, por sua vez, visa apoiar a implementação de cursos regulares de licenciatura em Educação do Campo nas instituições públicas de ensino superior - IES de todo o país, direcionados para a formação de professores para a docência nos anos finais do ensino fundamental e ensino médio nas escolas rurais. Este processo de crescimento de ações governamentais que visam a uma formação específica para os povos do campo vem corroborar com os enunciados da I Conferência Nacional "Por uma Educação Básica do Campo”.

\footnotetext{
10 Disponível em http://portal.mec.gov.br/pet/194-secretarias-112877938/SECAD-educacao-continuada223369541/18725-escola-da-terra. Acesso em 05/01/2018.

11 Disponível em http://portal.mec.gov.br/busca-geral/215-noticias/568057805/65411-gestores-doprojovem-campo-se-reunemem-brasilia-para-curso-de-formacao. Acesso em 05/01/2018
} 
Desde a realização da I Conferência Nacional "Por uma Educação Básica do Campo", realizada em 1998, até o lançamento do primeiro Edital do Ministério da Educação para apoiar a oferta dessas Licenciaturas, início de 2008, dez anos se passaram. Durante todo esse período, nos encontros locais, regionais e nacionais de Educação do Campo, sempre constou como prioridade dos movimentos sociais a demanda por uma política de apoio à formação de educadores (MOLINA, 2009, p.185).

O Procampo se inseriu em uma das necessidades básicas para se pensar em educação na perspectiva dos movimentos sociais ligados a terra: a formação dos profissionais que atuam e atuarão nas comunidades campesinas. Essa formação tem que pressupor, segundo Molina (2009), a visão de educação como prática social. O educador do campo precisa perceber a escola como locus capaz de gestar um processo de transformação mais amplo. A escola é parte fundamental em qualquer política de formação de cidadãos e o professor precisa estar bem preparado para desenvolver essa consciência em seus educandos.

Os cursos de Licenciatura do campo inscrevem-se dentro de propostas políticas que podem ser inovadoras para a escola e para as relações sociais, pois, numa sociedade de classes, com interesses diferenciados, o compromisso com o trabalhador do campo e com a escola que interessa aos setores populares é parte da disputa hegemônica para a conquista de uma sociedade mais justa (MENEZES NETO, 2009, p.25).

Para alterar o status quo vigente no campo, a escola precisa se tornar um projeto coletivo. Os professores têm de manter aberto e incentivar um diálogo direto com a comunidade. A educação para transformação requer a participação coletiva dos sujeitos do campo, pois o “[...] processo pedagógico é um processo coletivo e por isto precisa ser conduzido de modo coletivo, enraizando-se e ajudando a enraizar as pessoas em coletividades fortes. Educadores e educandos constituem a coletividade da escola” (CALDART, 2009, p.123).

Em 2010, é assinado o Decreto 7.392, de 04 de novembro, que “dispõe sobre a política de educação do campo e o Programa Nacional de Educação na Reforma Agrária PRONERA" (BRASIL, 2018)12. Acrescente-se que em 2012, a assinatura, pela presidente Dilma Rousseff, do Programa Nacional de Educação do Campo - Pronacampo, que tem como um de seus eixos a formação de profissionais para as escolas do campo possibilitou

\footnotetext{
${ }_{12}$ Disponível em http://portal.mec.gov.br/docman/marco-2012-pdf/10199-8-decreto-7352-de4-de-novembrode-2010/file. Acesso em 06/01/2018.
} 
segurança pedagógica e jurídica, sejam para ações ligadas ao PRONERA, de modo mais amplo, seja para o planejamento estratégico de oferta de vagas e acompanhamento da Educação do Campo no Brasil.

Como observa-se, de 2002 a 2012, houve momentos profícuos e singulares no que se refere à garantia da oferta de educação para os povos do campo. Perceber-se que alguns momentos políticos foram mais atrelados à luta dos trabalhadores do campo, outros menos; entretanto, foi um período ímpar na História da Educação brasileira e na formação de profissionais para educação nas escolas do e no campo no país. Entretanto, não há um processo de valorização desse profissional. Ao contrário. De acordo com Oliveira (2013, p. $52)$,

as condições às quais são submetidos os profissionais da educação nas distintas redes públicas de ensino no país têm sido objeto de preocupação da sociedade. Os baixos salários, a falta de perspectiva na carreira, a carga de trabalho e problemas de infraestrutura que afetam diretamente a prática docente são apontados como fatores preocupantes por pesquisas acadêmicas, pelos sindicatos, pela imprensa e pela sociedade em geral. Existe certo consenso de que a profissão docente, referindo-se aos profissionais que atuam na educação básica, sofre um processo de desvalorização há décadas, sendo que a condição desses profissionais é muito variável no país, dependendo da rede em que são contratados, da etapa de ensino em que atuam e até mesmo da formação que receberam.

Conclui-se, pela citação acima, que aflora a tendência de o processo de formação de professores seguir, também, a lógica cruel do modelo econômico e social hegemônicos, o qual a História da Educação nos mostra que o panorama traçado por Oliveira (2013), ainda continua recente e presente em nossa sociedade. Dessa forma, a educação ofertada ao "povo" sofre com a precarização do trabalho desses profissionais, que adentram as escolas já com a carga desse estigma.

\section{Política de formação de professores para o campo no Brasil}

Da luta dos movimentos sociais do campo veio a conquista dos primeiros cursos de Formação de Professores para Educação do Campo no âmbito da SECAD/MEC ${ }^{13}$. A conquista da implantação trouxe consigo possibilidades e limites. Em nome da "autonomia universitária”, todo processo de implementação desses cursos ficou a cargo das IFES, tanto

\footnotetext{
${ }^{13}$ As nomenclaturas usadas no texto - SECAD ou SECADI - se referem à temporalidade na qual os documentos ou editais foram publicados. Nesse sentido, quando há um Edital da SECAD, sua data é anterior a 2011.
} 
no que diz respeito à organização dos Projetos Pedagógicos de Curso - PPC, quanto aos processos de seleção do pessoal técnico-docente, quanto na forma de acompanhamento, avaliação, gestão dos recursos, dentre outros. Por não haver uma Diretriz Nacional para estes cursos, parece-nos que cada universidade estabeleceu seus critérios de condução para tais licenciaturas.

No contexto dos movimentos sociais, houve o entendimento de que a seguridade à educação para os povos do campo não se daria somente pela existência de prédios escolares no espaço rural ou pelo atendimento, via deslocamento, em escolas no espaço urbano. Era necessário que o Estado fosse tencionado a garantir uma série de princípios para que a Educação do Campo pleiteada e realizada “com” os sujeitos do campo, primordialmente, com os sujeitos organizados em movimentos sociais, fosse implementada de fato. A existência de materiais didáticos próprios, organização diferenciada de tempos e espaços, metodologias, projetos político-pedagógicos, currículos, professores e profissionais específicos, fizeram parte das demandas do movimento para materialização da Educação do Campo.

É necessário salientar que, na História recente da Educação brasileira, a especificidade da formação em nível superior de professores para docência na Educação do Campo não tem sua gênese no MEC, mas, no Ministério do Desenvolvimento Agrário MDA. Ministério este que fomentou as ações do Programa Nacional de Educação na Reforma Agrária - PRONERA, notadamente em parceria com o Movimento dos Trabalhadores Rurais sem Terra. O primeiro curso de formação de educadores para o campo, oriundo da parceria do MDA, através do PRONERA, iniciado em 2002, conjuntamente com a Universidade Regional do Noroeste do Estado do Rio Grande do Sul - UNIJUÍ, teve como foco " $[\ldots .$.$] a formação acadêmica de professores que atuavam no interior de escolas e$ processos educativos do MST” (MARTINS, 2012, p. 107).

Embora experiências distintas, as iniciativas de instituição do Curso de Pedagogia da Terra e as reivindicações para uma política de Educação do Campo no interior do Estado, neste caso, devidamente arraigadas no MEC, fizeram parte de uma mesma demanda. Para Martins (2012, p. 105),

[...] não é possível dissociar as duas abordagens, uma vez que ambas, Pedagogia da Terra e Educação do Campo, são propostas educativas construídas coletivamente pelos sujeitos do campo, condizentes com as suas especificidades e com a sua perspectiva contra-hegemônica de campo, agricultura, educação e sociedade. 
Pela tessitura dos acontecimentos, parece correto afirmar que, a proposta educativa pleiteada pelos sujeitos sociais coletivos em prol da luta e da vida na terra, organizados no movimento conhecido como "Por uma Educação do Campo", além da manutenção e expansão dos cursos de Pedagogia da Terra, estreitou a pressão sobre o governo federal, sobretudo a partir da criação da SECAD, no ano de 2004, para se garantir a sua efetivação, como política de Estado. Esta materialização é considerada por teóricos ${ }^{14}$ do Movimento, como um dos marcos notáveis para a concretização das ações em prol da Educação do Campo na perspectiva de garantir-lhe espaço na agenda oficial do MEC.

O protagonismo da sociedade civil, através dos movimentos sociais, vem transformando a Educação do Campo nesses últimos anos, influenciando o início de uma política pública para atender às necessidades dos povos do campo no que se refere ao direito de terem uma educação pensada e realizada a partir do e no local onde vivem e que crie possibilidades para esta parcela da sociedade.

A escola do campo, demandada pelos movimentos sociais e econômicos do campo, cria uma conexão direta entre formação e produção entre educação e compromisso político. Uma escola que, em seus processos de ensino e de aprendizagem, considera o universo cultural e as formas próprias de aprendizagem dos povos do campo, que reconhece e legitima estes saberes construídos a partir de suas experiências de vida. Uma escola que se transforma em ferramenta de luta para a conquista de seus direitos de cidadãos (ANTUNES-ROCHA, 2009, p.40).

Ao se discutir a educação do homem do campo, é preciso que se perceba, na visão da autora que, dentro de uma determinada comunidade, a escola tem o potencial de agregar múltiplas experiências e visões de mundo. Tais experiências se encontram ligadas às vidas dos sujeitos que ali se inserem. É na escola que acontecem reuniões entre a comunidade e é onde os pais dos alunos se encontram. Esse processo de união não deve ser neutro ou ingênuo. Ele precisa ser político, à medida que os membros sejam incentivados a discutir, refletir e pensar vários aspectos de suas vidas, iniciando pela escola dos filhos e o objetivo da educação que estes estão tendo. Por isso, a visão de formação de professores precisa ser mais ampla. Segundo Martins (2008, p. 40),

no âmbito da escola, a formação de professores faz parte de um projeto de sociedade que deve estar bem claro e ser almejado pela comunidade escolar. Assim, necessita estar inserido na construção coletiva da escola, [...] a

\footnotetext{
${ }^{14}$ Cf. Munarim, 2011.
} 
formação de professores, além de partir da compreensão da divisão de classes causada pelo sistema capitalista, necessita fazer da educação um instrumento de superação da situação limite na qual estamos imersos.

Este debate pode se estender à análise das possibilidades de mudanças, fortalecimento e crescimento da economia local, ou seja, das condições de produção dos bens necessários à sobrevivência dos que ali habitam. Em 2012, com Edital Conjunto SESU-SETEC-SECADI$\mathrm{MEC}^{15}$, mais possibilidades foram lançadas. À época, almejavam-se o aumento da oferta de vagas com professores efetivos nas universidades e a institucionalização do curso. Não mais a materialização de cursos por programas, mas a oferta de licenciaturas que trouxessem já o acúmulo de experiências advindas dos movimentos sociais e dos programas de Educação do Campo precedentes. Outra possibilidade vislumbrada foi a melhoria de aprendizagem dos alunos da Educação Básica de escolas do campo, pois em alguns anos teriam, como professores, os egressos das licenciaturas em Educação do Campo, já institucionalizadas nas Universidades. Cabe, agora, analisar os frutos dessa "conquista”.

Ao longo dos anos, desde sua criação até os dias atuais (2018), a SECAD (I) lançou três editais do Programa de Apoio à Formação Superior em Licenciatura em Educação do Campo - Procampo, a saber: n. 2, de 23 de abril de 2008 (SECAD); o n. 09 de 29 de abril de 2009 (SECAD) e o edital n. 02 de 31 de agosto de 2012 (SECADI). Os editais guardam estreitas semelhanças entre si.

A importância de se analisar o teor dos editais está no fato de que, como documentos oficiais, tornam público o entendimento da SECADI/MEC quanto aos parâmetros mínimos considerados nas propostas de formação de professores para a Educação do Campo.

Voltando o foco para o estudo dos editais quanto ao seu modelo de fomento, os de 2008 e 2009 previram somente auxílio financeiro e apenas para custeio, no montante de $\mathrm{R} \$$ 4.000,00 per capta por aluno/ano, durante o período de vigência, ou seja, do início ao fim das turmas, formadas com 60 alunos, e pela determinação constante em edital, chegou-se ao total de $\mathrm{R} \$$ 240.000,00. Com esta verba foi possível arcar com despesas de pessoa física (contratação de professores, técnicos, dentre outros), materiais de consumo (materiais pedagógicos, combustível, alimentação) e despesas com pessoa jurídica (contratação de serviço de hospedagem, aluguel, reprodução de materiais, dentre outros).

\footnotetext{
15 Trata de um edital que envolveu mais de uma secretaria do Ministério da Educação. São elas: Secretaria de Educação Superior - SESU; Secretaria de Educação Profissional e Tecnológica - SETEC, e Secretaria de Educação Continuada, Alfabetização, Diversidade e Inclusão - SECADI.
} 
Nas restrições impostas à execução desse orçamento destacaram-se: a impossibilidade do pagamento de bolsas aos professores e alunos, despesas com construção de prédios, aquisição de material permanente e livros. Estas restrições, na medida em que lhes couberam, contribuíram significativamente para a inexistência nas IES, por exemplo, de salas, alojamentos, carros, ônibus, refeitórios, acervos bibliográficos, aparelhos multimídia para os cursos de Licenciatura em Educação do Campo. Nos editais lançados não houve alteração quanto às finalidades desse valor de custeio, fator que contribuiu para a ausência de um possível legado material de assistência para acesso e permanência desses discentes na Educação Superior advindo do financiamento específico dos cursos.

Tal necessidade, de ampliação da aplicação do valor destinado anualmente às turmas abertas no bojo do Procampo, perpassou as reuniões nacionais das Licenciaturas em Educação do Campo organizadas pela SECADI/MEC. A resposta obtida, via de regra, foi ao encontro da negativa amparada pelas restrições impostas ao tipo de financiamento dirigido aos cursos. Se o edital de 2008, ao fazer referência, nas bases legais, à Instrução Normativa STN nº 01 de 15.01.1997, não deixava claro a restrição de aplicação dos recursos apenas ao custeio dos cursos, o edital de 2009 o fez.

Ao enumerar as bases legais que deveriam amparar as propostas, apresentou clara referência à Resolução/CD/FNDE $\mathrm{n}^{\circ}$. 06 de 17.03.2009. A leitura desta referência, especificamente o artigo $1^{\circ}, \S 3^{\circ}$ desatou o imbróglio das possibilidades de utilização dos recursos da seguinte forma: "a assistência financeira de que trata esta resolução não prevê concessão de bolsas nem despesas de capital”. Este pressuposto legal avançou, também, ao edital de 2012, que se diferenciou por ser dirigido à implantação efetiva de cursos com oferta regular dentro do quadro periódico de vagas das Instituições de Ensino Superior.

Para que a implantação dos cursos de Licenciatura em Educação do Campo se efetivasse, o edital de 2012 trouxe importantes alterações que, por sua vez, coadunaram em mudanças no panorama de oferta do Procampo, em nível nacional, ao permitir, apenas, a participação das Universidades Federais e Institutos Federais ${ }^{16}$. Essa mudança é compreensível pelo modelo de fomento oferecido às instituições selecionadas no âmbito do edital, tendo em vista que, além do financiamento de custeio, trouxe a possibilidade de contratação de pessoal - docente e técnico - para o quadro das universidades e institutos. Tal

\footnotetext{
${ }^{16}$ Em 2010, de acordo com dados do MEC, eram 32 instituições com turmas do Procampo aprovadas, das quais, 6 Autarquias, 6 estaduais, 3 regionais, 17 federais, 1 fundação. A relação nominal das instituições ofertantes de turmas do Procampo pode ser obtida em: http://portal.mec.gov.br/index.php?option=com_ docman\&view=download\&alias $=6463$-procampo-20 10-tabela\&category_slug=agosto-2010-pdf\&Itemid $=30$ 192. Acesso em: 20/07/2015.
} 
ação, contratação de pessoal, dificilmente seria articulada nos âmbitos fora das determinações e ações da SESU ${ }^{17}$, unidade do MEC responsável por planejar, orientar, coordenar e supervisionar o processo de formulação e implementação da Política Nacional de Educação Superior, de modo que não se estendeu a instituições estaduais, autarquias, fundações, como ocorreu nos editais anteriores do Procampo.

Quanto à contratação de pessoal, a SESU, em 2013 e 2014, havia destinado a cada universidade participante as 15 vagas previstas para professores efetivos, bem como as 3 vagas para provimento de técnicos, sendo 1 vaga para nível superior e 2 vagas para nível médio, indicando ampliação de docentes e funcionários administrativos permanentes. Já para os quatro Institutos Federais selecionados, a destinação dessas vagas dependeria da avaliação da SETEC e do cumprimento do Termo de Acordo de Metas Institucionais, principalmente no que se referia ao banco de horas dos professores e na disponibilidade de carga horárias excedentes nos Institutos.

O processo de seleção/contratação desse pessoal foi totalmente planejado e executado pelas IES, em conformidade com a autonomia legal e as atribuições das mesmas. Este é um ganho considerável dentro das instituições e um legado que não se pode perder dentro da estrutura administrativa das IFES, o que requer vigia constante quanto aos fins para os quais este pessoal foi selecionado.

\section{Algumas Conclusões}

Numa breve retrospectiva das ações e políticas de formação de professores em nível superior para Educação do Campo empreitadas pelo MEC, constata-se que, desde 2006, já se estudava, no âmbito da Secretaria de Educação Continuada, Alfabetização e Diversidade SECAD, uma proposição de curso de Licenciatura em Educação do Campo. Em 2008 e 2009, através de financiamento do Fundo Nacional de Desenvolvimento da Educação - FNDE, a SECAD convocou as Instituições de Educação Superior (IES) públicas para apresentarem propostas para abertura de turmas do Procampo.

Em 2012, eram 33 IES (Estaduais, Federais, Fundações, dentre outras) desenvolvendo turmas apoiadas pelo Procampo, alocadas em 18 estados e no Distrito Federal. Em 2012, no dia 20 de março, foi lançado o Programa Nacional de Educação do Campo - Pronacampo (que englobou o Procampo como um de seus eixos de ação para

17 Disponíveis em: http://portal.mec.gov.br/index.php?option=com_content\&view =article\&id=287\&Itemid =354. Acesso em: 12/08/2014. 
formação de profissionais para Educação do Campo), com objetivo de oferecer apoio técnico e financeiro aos estados, Distrito Federal e municípios para implementação da Política Nacional de Educação do Campo. O Edital Conjunto 02/2012 SESU/SETEC/SECADI/MEC, advindo do desdobramento das políticas do Pronacampo, trouxe a possibilidade da institucionalização de 44 cursos de Licenciatura em Educação do Campo. Diferentemente de seus predecessores, o edital de 2012 se destinou apenas às instituições federais: universidades e institutos e não mais às universidades públicas em geral. Todo este movimento que deu origem aos editais da SECADI/MEC instigou-nos a desenvolver um estudo sobre tal temática.

A Educação do Campo propõe um modelo em que haja a centralidade no conhecimento dos sujeitos do campo, viabilizada pela participação dos movimentos sociais ligados à terra, desde o planejamento até a concretização de ações educativas, ou seja, não se faz esta educação sem essa participação ativa e propositiva desses sujeitos coletivos. Nesse cenário, a formação de um professorado específico e conhecedor da historicidade, da memória, das lutas, dos direitos adquiridos, dos debates e conquistas desses povos, se tornou condição na garantia de chegarem a alcançar um projeto de país com fortes tendências agrícolas sustentáveis e que valorize a produção familiar.

\section{Referências}

ANTUNES-ROCHA, M. I. \& MARTINS, A. A. (Org..). Educação do Campo: desafios para a formação de professores. Belo Horizonte: Autêntica, 2009.

BRASIL. Lei de Diretrizes e Bases da Educação Nacional, n. 9.394. Brasília, 1996 . Conselho Nacional de Educação Câmara de Educação Básica. Diretrizes Operacionais para a Educação Básica nas Escolas do Campo. Parecer nº 36/2001.

Conselho Nacional de Educação Câmara de Educação Básica. Diretrizes Operacionais para a Educação Básica nas Escolas do Campo. Resolução n ${ }^{\circ} 1$ de 03 de abril de 2002.

Secretaria de Educação Continuada, Alfabetização e Diversidade -SECAD. Edital $n$. o2 de 23 de abril de 2008. Brasília, 2008.

Secretaria de Educação Continuada, Alfabetização e Diversidade-SECAD. Edital n. o9 de 29 de abril de 2009. Brasília, 2009.

.Presidência da República-Casa Civil/Sub-Chefia Para Assuntos Jurídicos. Decreto $n^{o}$ 7.352/2010. Dispõe sobre a política de educação do campo e o Programa Nacional de Educação na Reforma Agrária, de 4 de novembro de 2010. 
Revista Educação e Políticas em Debate - v. 7, n. 1, p. 77-94-jan./abr. 2018 - ISSN 2238-8346

BRASIL. Secretaria de Educação Continuada, Alfabetização e Diversidade - SECADI. Edital Conjunto SESU/SETEC/SECADI/MEC, n. O2 de 31 de agosto de 2012. Brasília, 2012.

CALDART, R. S. Pedagogia do Movimento Sem Terra. Petrópolis: Vozes, 2000.

CALDART, R. S. O MST e a formação dos Sem Terra: o movimento social como princípio educativo. São Paulo: Estudos Avançados, 2001.

CALDART, R. S. A Escola do Campo em Movimento. In: ARROYO, Miguel Gonzalez; CALDART, Roseli Salete; MOLINA, Mônica Castagna (Org.). Por uma Educação do Campo. 4. ed. Petrópolis: Vozes, 2009.

COSTA, S. A.\& BEZERRA NETO, L. Políticas públicas/estatais: contribuição para o estudo da relação estado-sociedade. Acta Scientiarum Education. Maringá, v. 38, n. 2, p. 165-172, Abr.-Jun, 2016.

IANNI, O. Origens Agrárias do Estado Brasileiro. São Paulo: Brasiliense, 1984.

LIMA, J. S. P. Banco Mundial e sistema de ensino superior: desenvolvimento ou controle externo. Dissertação de Mestrado. Universidade Federal de Santa Catarina, 2004.

MARTINS, F. J. A Pedagogia da Terra: os sujeitos do campo e do ensino superior. Educação, Sociedade E Culturas, Porto-PT, nº 36, p. 103-119, 2012.

. (Org.). Educação do Campo e Formação Continuada de Professores: uma experiência coletiva. Porto Alegre: EST Edições, 2008.

MARTINS, L. M. Análise sócio-histórica do processo de personalização de professores. Tese de Doutorado. Programa de Pós-graduação em Educação, Faculdade de Filosofia e Ciências, UNESP. Marília, 2001.

MARTINS, L. M.; DUARTE, N. (Org..) Formação de professores: limites contemporâneos e alternativas necessárias [online]. São Paulo: UNESP; São Paulo: Cultura Acadêmica, 2010.

MENEZES NETO, A. J. Formação de professores para a Educação do Campo: projetos sociais em disputa. In: ANTUNES-ROCHA, M. I.; MARTINS, A. A. (Org.). Educação do Campo: desafios para a formação de professores. Belo Horizonte: Autêntica, 2009.

A Igreja Católica e os movimentos sociais do campo: a Teologia da Libertação e o movimento dos Trabalhadores Rurais sem Terra. Caderno CRH, Salvador, v. 20, n. 50, p. 331-341, mai/ago, 2007.

MUNARIM, A. A Educação do Campo no Cenário das políticas públicas na primeira metade do século 21. Em Aberto, v.24, n. 85. Brasília: Inep, 2011.

OLIVEIRA, D. A. As políticas de formação e a crise da profissionalização docente: por onde passa a valorização? Revista Educação em Questão, Natal, v. 46, n. 32, p. 51-74, maio/ago. 2013. 
OLIVEIRA, M. A de. As bases filosóficas e epistemológicas de alguns projetos de educação do campo: do pretendido marxismo à aproximação ao ecletismo pós-moderno. Curitiba, UFPR, Setor de Educação, Tese, 2008.

SANTOS, L. L. de C. P. Implementação de políticas do Banco Mundial para Formação Docente. Cadernos de Pesquisa, n. 111, dez, 2000.

SCHERER-WARREN, I. Cidadania sem fronteiras: ações coletivas na era da globalização. São Paulo: Hucitec, 1999. 